\title{
Hongos Fitopatógenos Asociados Al Tomate (Solanum Lycopersicum L.) En La Zona Árida Del Noroeste De México: La Importancia De Su Diagnóstico
}

\author{
Francisco Eleazar Martínez-Ruiz
}

Estudiante del programa, Doctoral en Cs Agropecuarias del Instituto de Ciencias Agrícolas, Universidad Autónoma de Baja California

Lourdes Cervantes-Díaz, Dr.

Carlos Enrique Aíl-Catzím, Dr.

Instituto de Ciencias Agrícolas. Universidad Autónoma de Baja California.

Ejido Nuevo León, Mexicali, Baja California, México

Luis Guillermo Hernández-Montiel, Dr.

Centro de Investigaciones Biológicas del Noroeste. Avenida instituto politécnico nacional 195, colonia Playa palo de Santa Rita Sur, La Paz, Baja

California Sur, México

Carmen Lizette Del Toro Sánchez, Dr. Edgar Omar Rueda-Puente, Dr.

Universidad de Sonora, Departamento de Agricultura y Ganadería, Carretera a Bahía de Kino km. 21. Hermosillo, Sonora, México

doi: 10.19044/esj.2016.v12n18p232 URL:http://dx.doi.org/10.19044/esj.2016.v12n18p232

\begin{abstract}
Tomato crops are among the most important vegetables cultivated worldwide, Mexico being one of the major producing countries. Large quantity of this crop is found in states belonging to the arid northwest of the country; the adaptation of these regions to vegetable production has been significant with the support of agricultural technology due to the use of protective structures for plants, such as greenhouses and shaded mesh. However, pests and diseases are a major biotic factor that significantly reduces production. There are more than 200 diseases associated with the nightshade of various etiologies. The process of identifying the cause of a disease in plants is called diagnosis. The diagnosis of plant diseases has been described as an art and a science; it requires scientific knowledge of plant pathology and related disciplines. Effective disease control requires making the best possible decisions to reduce the risk of serious production losses. Control strategies based on prevention of disease and methods that slow the spread of such diseases. Therefore, proper management of diseases affecting
\end{abstract}


the tomato crop, knowledge and understanding of the diagnosis and its infectious cycle is vital and to establish effective control measures.

Keywords: Tomato, Diagnosis, Diseases, Fungi

\section{Resumen}

El cultivo de tomate se encuentra entre las hortalizas de mayor importancia a nivel mundial, encontrándose México dentro de los principales países productores. Éste cultivo se localiza en importante cantidad en estados pertenecientes a las zonas áridas del noroeste del país; la adaptación de estas regiones a la producción de hortalizas ha sido significativa con el apoyo de tecnificación en los cultivos considerando el uso de estructuras de protección para las plantas, como es el caso de invernaderos y malla sombra. No obstante, las plagas y enfermedades son un factor biótico primordial que merma significativamente la producción. Existen más de 200 enfermedades asociadas a las solanáceas de diversas etiologías. El proceso de identificar la causa de una enfermedad en plantas se denomina diagnóstico. El diagnóstico de enfermedades de plantas ha sido descrito como un arte y una ciencia, requiere de conocimiento científico de la fitopatología y disciplinas conexas. El control eficaz de las enfermedades requiere conseguir que las mejores decisiones posibles reduzcan el riesgo de pérdidas serias de producción. Las estrategias de control se basan en la prevención de las enfermedades y en métodos que ralenticen la propagación de dichas enfermedades. Por lo anterior, el adecuado manejo de las enfermedades que afectan al cultivo del tomate, el conocimiento y entendimiento del diagnóstico y de sus ciclos infectivos es de vital importancia y poder establecer medidas de control efectivas.

Palabras clave: Tomate, Diagnóstico, Enfermedades, Hongos.

\section{Introducción}

Las zonas áridas producen el 60\% de los alimentos a nivel mundial (De Santa Olalla et al., 2005). Una de las zonas de relevancia en la producción de alimentos en la República Mexicana, es el noroeste de México, el cual está conformado por los estados de Baja California, Baja California Sur, Chihuahua, Sinaloa y Sonora. Las condiciones que prevalecen en esta región van desde los 50 a 230 mm de precipitación anual, con temperaturas que oscilan en los meses de verano entre los 38 los $52^{\circ} \mathrm{C}$; una marcada fluctuación de temperaturas diurna/ nocturna y de la velocidad del viento; baja disponibilidad de agua, debido a la alta evaporación; una radiación solar incidente; los suelos de estas zonas son variables en profundidad, textura, $\mathrm{pH}$ alcalinos, conductividad eléctrica altas y baja 
fertilidad; en ellos se acumulan carbonato y la tasa de infiltración del horizonte cálcico depende del contenido de carbonato (Mazuela, 2013); la intrusión salina se enfatiza provocando que las conductividades eléctricas varíen entre los 2 a los 8 decisiemens, ensalitrando los pozos de agua utilizados para la agricultura y lleguen a contener hasta $8 \pm 4$ gr L agua de solidos disueltos.

Las severas limitaciones que se presentan para la agricultura en las zonas áridas en el noroeste de México, han promovido que los productores y técnicos busquen ser más eficientes en el uso de recursos, lo que ha implicado la adopción de nuevas tecnologías; otro factor que ha influenciado esta tendencia es la exigencia cada vez mayor del mercado globalizado por productos de alta calidad. En este tipo de zonas se ha consolidado la producción de varias hortalizas, las cuales se comercializan en su mayoría hacia Estados Unidos, la Unión Europea, Canadá y Japón (Villa y Bracamonte, 2012). Por estas razones la horticultura es una actividad de importancia tanto en el plano social como en el económico, por la captación de divisas así como por la generación de empleos al ser, en su gran mayoría, altamente demandante de mano de obra, como es el caso del tomate (Sandoval, 2004).

En el año 2014, la producción de tomate en la República Mexicana fue de aproximadamente 2, 326,000 t, de la producción total. A nivel nacional el estado de Sinaloa aporta el 42.4\%, Baja California 7.7\%, Jalisco 6.6\%, Zacatecas 6.1\%, San Luis Potosí 5.9\%, Michoacán 5.3\%, Baja California Sur 4.9\% y Sonora con 4\% (SIAP, 2015). Sonora cuenta con 1705 ha de tomate: $15 \%$ en invernadero, $75 \%$ en casa sombra y $10 \%$ a cielo abierto (Borboa-Flores et al., 2009).

En el noroeste de México, específicamente en el Estado de Sonora, su producción se ha visto afectada por la aparición de enfermedades que causan pérdidas hasta en un $100 \%$. Para que se desarrolle la enfermedad tiene que estar presente en el ambiente adecuado un huésped, susceptible y un patógeno virulento, de tal forma que la interacción del huésped, patógeno y ambiente tenga como resultado un daño del huésped. Los vectores de los patógenos pueden desempeñar una parte integral en el desarrollo y programación de las enfermedades, especialmente las enfermedades víricas y los marchitamientos bacterianos (Figueroa et al., 2007; Rodríguez-Caro, 2009; Borboa-Flores et al., 2009).

Entre los factores bióticos que sobresalen como agentes de enfermedades de Solanum lycopersicum son las causadas por fanerógamas parasitarias, bacterias, fitoplasmas, virus, viroides, nematodos, insectos y hongos. Para el caso específico de los hongos, estos son plantas septadas o aseptadas que carecen de clorofila. Normalmente están ramificados y son filamentosos. Entre los organismos que ocasionan estas enfermedades 
destacan los hongos como son Botrytis cinerea, Alternaria dauci f. solana, Laveillula taurina, Phytopthora infestans (Mont.) de Bary, Pythium aphanidermatum, Fusarium oxysporum y Rhizoctonia solani (Flores et al., 2008). El objetivo del presente trabajo consiste en generar estrategias de control y un adecuado manejo de las enfermedades que afectan al cultivo del tomate en las zonas desérticas del Noroeste de México, para ello el conocimiento y entendimiento del diagnóstico de los agentes causales y de sus ciclos infectivos es de vital importancia.

\section{La importancia de la agricultura en zonas áridas del noroeste de México: El cultivo de tomate}

Aproximadamente un tercio de las áreas continentales de la tierra está cubierto por zonas áridas y semiáridas. Estas regiones son afectadas por diversos procesos de degradación de tipo fiscos, químicos y biológicos. Se estima que una de las causas más importantes de degradación ha sido el empleo de técnicas de agricultura intensiva, generadas para sistemas menos frágiles y con características edafoclimáticas muy diferentes a las del trópico seco americano. Las zonas desérticas han sido consideradas de bajo potencial agrícola, sin embargo, estas tierras pueden ser altamente productivas si son manejadas de forma adecuada (Díaz, 2001). Tal es el caso de la insuficiencia constante de precipitaciones, la elevada evaporación, agua de riego y suelos de baja calidad que son algunas de las causas del porqué las zonas áridas se encuentran consideradas como terrenos no afables para la producción de alimentos. No obstante, estas restricciones, aunado a la ascendente demanda de productos agrícolas ha propiciado que la agricultura en zonas desérticas tenga un importante desarrollo (López-Aguilar et al., 2008). Los altos rendimientos de producción en los cultivos agrícolas en la zona árida del noroeste de México, es consecuencia, a la eficiencia tecnológica de los productores motivada por las limitaciones climáticas, así como también al ascendente desafío propuesto por los mercados internacionales (Rodríguez, 2003). Por ejemplo, la conversión de cultivos constituidos solamente por básicos hacia productos con superior concentración en precio agregado, permite un importante crecimiento en la productividad de esta región agrícola (Rodríguez, 2013). En el noroeste de México, la producción de hortalizas específicamente la de Lycopersicum esculentum, representa un alto valor comercial. El grado de tecnificación influye de una manera muy considerable para el rendimiento del tomate, dentro de estos paquetes tecnológicos se incluye el uso de estructuras para proteger a las plantas de las inclemencias climáticas, prácticas de manejo como lo es la selección de variedades con potencial para la zona, así como también un adecuado manejo de plagas y enfermedades que afectan al cultivo. (Berenguer, 2003). Gracias a una alta productividad la zona semiárida es una de las zonas agrícolas de 
mayor importancia en el noroeste de México, conformada por alrededor de 200,000 hectáreas que con la tecnificación está permitiendo aumentar la producción, reflejándose en el derrame de divisas y generación de empleos (Rodríguez, 2003).

A nivel mundial en gran cantidad de países, el tomate (Solanum lycopersicum), se considera como una de las hortalizas más importantes debido a su alta demanda por factores como su valor nutricional así como su uso a nivel industrial, esta producción ha ido en aumento en los últimos años, entre los principales países productores se encuentra México (HernándezHerrera et al., 2014; FAOSTAT, 2015). La producción obtenida ha incrementado mundialmente $9.5 \%$ en los últimos cuarenta años. A nivel nacional el cultivo se encuentra entre las hortalizas más importantes debido a los niveles de producción, sembrándose alrededor de 81,000 ha donde se obtienen cerca de 2 millones de toneladas. Los principales estados productores son Sinaloa, Baja California, San Luis Potosí, Sonora, Nayarit, Morelos y Michoacán (Jiménez, 2003; SAGARPA, 2005; FAOSTAT, 2015). Factores y la importancia del diagnóstico fitosanitario. De acuerdo a Borboa et al. (2009), en el ámbito de las Ciencias Agronómicas y la fitoprotección, el panorama que se ofrece a la profesión va más allá de la relación simplista patógeno-químico o patógeno-variedad resistente. Los profesionales tienen la obligación de responder como conocedores del área, con una conceptualización clara y una estructura operativa funcional y ética. En la medida en que se limita la responsabilidad profesional únicamente a la detección del agente causal y a su supresión por medios físicos o químicos, el profesional se estará volviendo redundante, porque los avances tecnológicos permiten que esa función la cumpla un técnico calificado en el manejo de los instrumentos de laboratorio. El control de enfermedades con su concepción ecológica enfatiza como primer fundamento, el diagnóstico correcto del problema fitosanitario; basados en el diagnóstico, el agricultor o asistente técnico pueden seleccionar las estrategias y tácticas de manejo apropiadas.Existen por lo menos dos grupos de técnicos que desempeñan actividades de diagnóstico: a) extensionistas en sanidad vegetal, asistentes técnicos, y funcionarios de empresas de agroquímicos, el cual es un grupo responsable del acierto o el fracaso de los profesionales de la fitoprotección a nivel del agricultor; b) profesionales dedicados a las clínicas de identificación y diagnóstico, los cuales tienen una preparación taxonómica y es un grupo exigente en la nitidez de la identificación y caracterización; llegan a tener gran experiencia en las principales enfermedades de un cultivo en particular (Bustamante y Rivas, 1999).

Las decisiones más frecuentes a nivel del cultivo son las siguientes: a) con base en un diagnóstico correcto, se toman las medidas de manejo de la enfermedad; b) para diagnosticar un problema fitosanitario cuya naturaleza e 
identidad no es reconocida por el agricultor o asistente técnico, se recolectan muestras e información de campo y se recurre a especialistas antes de definir las tácticas de manejo y, c) aunque no se tiene conocimiento sobre la identidad de la enfermedad y las condiciones que le favorecen, se decide aplicar medidas de amplio espectro con la finalidad de acertar en su control. En los dos primeros casos se hace uso de la experiencia en diagnóstico para evitar riesgos de pérdidas en el cultivo e inversiones costosas de manejo. Sin embargo, en la tercera decisión se juega al azar por desconocimiento del agente causal y se cae en el error de la "automedicación" por propia decisión o por confiar en el consejo de otra persona con poca o ninguna experiencia en diagnóstico (Bustamante y Rivas, 1999).

Según Holguin y Rueda (2007), existen consideraciones generales del diagnóstico, sus fundamentos y procedimientos con énfasis en problemas fitopatológicos: qué es el diagnóstico y cuáles son sus niveles: el diagnóstico se puede definir como el arte científico de reconocer por observaciones, estudio o experimentación, la naturaleza de la causa de un problema y los factores que inciden en su desarrollo. El diagnóstico es una etapa fundamental en el ámbito de la fitoprotección. Para realizarlo se deben analizar las condiciones en que se presenta el problema, en especial el manejo del cultivo y las interacciones planta- agente causal- organismos benéficos- condiciones agroclimáticas, es decir, se requiere de un análisis integral que conlleve a un acertado juicio sobre la etiología del problema y los factores que lo favorecen. Este enfoque tiene gran aceptación en la actualidad, donde la protección del ambiente y la salud humana son una exigencia de primer orden y la producción sostenible y el Manejo Integrado de Plagas $=\mathrm{MIP}=$ son incorporados a los programas agrícolas a nivel mundial (Holguín y Rueda, 2007).

Asimismo, Holguín y Rueda (2007), indican que el diagnóstico se puede llevar a cabo a través de cuatro diferentes niveles, de acuerdo con su objetivo y la experiencia, recursos físicos y técnicos a disposición del profesional. 1. Nivel de campo: Se puede realizar en condiciones precisas que permitan identificar el agente causal por sus síntomas, signos, distribución en el campo u otros factores. En este caso, la experiencia con el cultivo y sus enfermedades es fundamental. Muchos asistentes técnicos en cultivos específicos no solo pueden identificar el problema principal, sino también otros de incidencia económica importante. 2. Diagnóstico de confirmación: cuando se presentan condiciones de campo que no permiten establecer la identidad de los organismos causales, es necesario reunir información de campo y recolectar muestras para análisis de laboratorio. Esto permite además de una clasificación más exacta y útil, la elaboración de las listas y mapas de distribución de enfermedades de una región. Es importante recordar que diferentes organismos o factores abióticos pueden 
ocasionar un síntoma similar en la planta; por lo tanto, se deben evitar los diagnósticos precipitados carentes de información. Cuando todos los rasgos característicos de la enfermedad no están presentes para llegar a un diagnóstico preciso, se puede dar un diagnóstico presuntivo, sujeto a una confirmación posterior. 3. Diagnóstico de nuevas enfermedades: en algunos casos, el agente causal del problema fitosanitario no es conocido, y se hace necesario iniciar un estudio interdisciplinario que permita determinar la naturaleza de la plaga y establecer la identidad exacta, con el fin de orientar su manejo. Este nivel de diagnóstico exige en muchos casos la disponibilidad de equipos, la participación de diferentes especialistas y el tiempo necesario para realizar un estudio clínico minucioso y analizar las condiciones de campo en que se presenta el problema. 4. Diagnóstico regional: en este nivel se utiliza toda la información de una enfermedad para que un equipo de trabajo pueda hacer el reconocimiento, en una zona o en un país, de la presencia de ésta y las condiciones en que se da. Este diagnóstico indica además la distribución, importancia y prioridad de la enfermedad para emprender una campaña de manejo o erradicación o una investigación más amplia, y serviría de base para establecer un servicio de información geográfica de agentes causales de la enfermedad. Además de la distribución de la plaga, también se puede conocer la presencia de algún tipo de resistencia de la planta o de enemigos naturales, así como problemas de fertilidad o estructura del suelo. Cuando la enfermedad no se conoce en un área o país se realiza unos reconocimientos negativo, donde se hace énfasis en la búsqueda del agente causal, con el fin de confirmar su ausencia o detectar su introducción. Para llevar a cabo estos cuatro niveles de diagnóstico se necesita de la participación de profesionales dedicados a diferentes actividades y de varias especialidades, lo cual confirma la importancia de la mayor integración entre funcionarios de extensión, sanidad vegetal e investigación, en una región o país.

\section{Elementos básicos del diagnóstico}

De acuerdo a Hernández et al. (2013), el profesional que realiza actividades de diagnóstico debe disponer de los siguientes elementos básicos: racionalidad, objetividad, conocimientos técnicos, equipo adecuado y habilidad para trabajar en grupo. Estos aspectos constituyen el punto inicial que un técnico dedicado a esta actividad debe considerar, a lo cual, con el tiempo se adicionan, mayores conocimientos y experiencias que lo llevan a convertirse en un experto. La racionalidad es el elemento del diagnóstico que orienta a una organización sistemática de las labores de campo y laboratorio, acordes con el conocimiento técnico-científico, con el fin de hacerlo más ordenado y preciso. El complemento a la racionalidad es la objetividad, factor que indica la necesidad de proceder de acuerdo a la existencia de una 
realidad para cada diagnóstico. La ausencia de este elemento expone al profesional a cometer errores por apresuramiento o exceso de confianza en su experiencia. Los conocimientos más utilizados por los profesionales en diagnóstico son: anatomía y diagnósticos subjetivos pueden darse por parte de especialistas, con costos innecesarios de control, pérdidas de cultivos y perjuicios para la comercialización internacional, así como pérdida de credibilidad, fisiología de las plantas, factores que predisponen el ataque de las enfermedades y problemas abióticos del cultivo; fenología del cultivo y la plaga, técnicas de manejo del cultivo y metodologías de diagnóstico. Cuando el área de diagnóstico se circunscribe a uno o dos cultivos, el nivel de conocimientos y precisión en el diagnóstico se adquiere en menor tiempo. En el caso de realizar diagnóstico de enfermedades en diversos cultivos es importante el apoyo de expertos en el cultivo y especialistas en diferentes áreas de fitoprotección (Bustamante y Rivas, 1999).

\section{Interferencia fisiológica del agente causal de enfermedad y expresión de síntomas}

De acuerdo a Rueda et al. (2009; 2013), las enfermedades y agentes abióticos que afectan las plantas pueden interferir uno o varios de los cinco procesos fisiológicos básicos: 1) absorción y transporte de agua y nutrimentos; 2) fotosíntesis y metabolismo; 3) transporte de fotosintatos; 4) desarrollo de frutos y 5) maduración y senescencia de tejidos.

1.- Absorción y transporte de agua y nutrimentos: el área de absorción (raíces y pelos absorbentes) puede ser afectada por patógenos del suelo, tales como Fusarium spp., Rhizoctonia spp., Pythium spp., Phytophthora spp., Erwinia spp., Meloidogyne spp. y Pratylenchus spp. Los insectos también contribuyen al deterioro de la raíz, especialmente los géneros Phyllophaga (Coleopt.: Scarabaeidae) y Diabrotica (Coleopt.: Chrysomelidae). La presencia de semilla recién germinada y plántulas desenterradas puede deberse a ratas, tuzas, ardillas o pájaros. Por su parte, las malezas pueden afectar el desarrollo radicular del cultivo por competencia y presencia de sustancias alelopáticas. Los principales factores abióticos que pueden afectar el sistema radicular son: sobrefertilización, sequía, inundación, exceso de sales solubles y herbicidas. Los síntomas más comunes asociados con esta interferencia son la necrosis, la pudrición de las raíces y tallos de las plantas ("damping off"), las agallas, el desarrollo de raíces adventicias, las decoloraciones típicas de deficiencias nutricionales en el follaje y frutos y la marchitez de la planta. Otros síntomas no fácilmente detectables son la disminución del tamaño de las hojas y su capacidad fotosintética. Los microorganismos patógenos que actúan sobre los haces vasculares, son en su mayoría hongos y bacterias tales como: Fusarium oxysporum (diferentes formas especiales de acuerdo con los cultivos), 
Verticillium spp., Pseudomonas solanaceracum (diferentes razas) y Phytophthora spp. El taponamiento del xilema por parte de estos organismos produce el síntoma clásico de marchitamiento, el cual en el caso de las bacterias puede ser reconocido por el flujo blanquecino, que se observa a partir del corte transversal de un trozo de tallo de la planta afectada, que se sumerje en agua. 2.- Fotosíntesis y metabolismo: las hojas pueden ser interferidas en su acción fotosintética por una capa de crecimiento micelial, como es el caso del mildiu polvoso de las hojas y las fumaginas, crecimientos de color oscuro de hongos como Capnodium sp. La maleza como plaga de competencia, puede interferir la radiación solar y disminuir el nivel de actividad fotosintética del cultivo. Sin embargo, el punto de intercepción más crítico, es la disminución del área foliar por la acción de insectos comedores de hojas y de patógenos que causan lesiones en el follaje e interfieren el metabolismo de proteínas y la producción de la clorofila. Mildius vellosos, royas, antracnosis, manchas y mosaicos, son algunos de los síntomas más comunes de las enfermedades causadas por hongos, bacterias, virus y fitoplasmas. Se pueden presentar efectos similares, como efecto de deficiencias de nutrimentos y fitotoxicidad de herbicidas hormonales y de contacto. 3.- Transporte de fotosintatos: el floema es la vía de movilización de los azúcares y metabolitos a sitios de crecimiento o almacenamiento, esta vía puede ser interferida por virus, fitoplasmas y protozoarios tipo Phytomonas, los cuales pueden necrosar el floema. Síntomas tales como hojas rojizas y encrespamientos se deben al exceso de azúcares en la hoja. Algunos hongos como Rhizoctonia solani al atacar el cuello del tallo en solanáceas como la papa, bloquea el floema e impide el desarrollo normal de tubérculos y causa la formación de tubérculos aéreos. 4.- Desarrollo de frutos: en el desarrollo de frutos se presentan dos interferencias, además del llenado incluido en el acápite anterior, que pueden generarse por elementos bióticos y abióticos. En primer lugar se puede observar la caída de frutos pequeños y flores por deficiencias nutricionales, insectos, bacterias, hongos y virus. Los patógenos más conocidos son Botrytis cinerea y Erwinia amylovora. El otro efecto conocido en frutos, es el reemplazo del tejido por crecimientos de estructuras de hongos, tales como esporas y esclerocios en granos y tubérculos. 5.- Maduración y senescencia de tejidos: las hojas y los frutos especialmente, presentan interferencias por patógenos, insectos y factores abióticos que aceleran la senescencia de los tejidos. En algunos casos, las condiciones de maduración y senescencia estimulan el ataque de hongos como Alternaria spp. en solanáceas, al disminuir el contenido de carbohidratos. En los frutos cualquier daño a la estructura física ocasionado por vertebrados e insectos y la acción de hongos y bacterias son los causantes de la mayoría de pudriciones y pérdida de vigor y germinación de semillas (Bustamante y Rivas, 1999). 
Aparte de estas cinco interferencias, es importante considerar el efecto sobre el meristemo apical que ocasionan los insectos. Asimismo, vertebrados, hongos y bacterias que atacan plántulas de monocotiledóneas y dicotiledóneas, en algunos casos, el daño es total y en otros la planta presentará deformaciones posteriormente (Bustamante y Rivas, 1999).

\section{Los hongos como agentes causales de enfermedades}

En México es importante la producción de tomate debido a que se encuentra en continuo aumento la demanda y producción del mismo. Sin embargo, en cuantiosas ocasiones su rendimiento se ve mermado por la incidencia de diversas plagas y enfermedades (Pelegrín et al., 2004). El cultivo de tomate se encuentra afectado por la presencia de diversos microorganismos patógenos los cuales son la principal causa de las enfermedades, dentro de los cuales se destaca la presencia de hongos. (Flores et al., 2008). A continuación se describen las principales enfermedades y su agente causal.

\section{Podredumbre gris (Botryotinia fuckeliana (De Bary) Whetrel. Ascomycetes: Helotiales. Anamorfo: Botrytis cinerea Pers.)}

El hongo Botrytis cinerea (Figura 1) es un importante patógeno de plantas cultivadas. Ha sido citado sobre más de 200 especies vegetales y puede provocar enfermedades desde el estado de plántula hasta la poscosecha. Según una encuesta reciente, los especialistas lo ubican en segundo lugar en importancia entre todos los hongos fitopatógenos conocidos (Dean et al., 2012). La enfermedad de moho gris, causada por dicho hongo, es una de las más severas, se encuentra afectando a flores, frutos y tallos. En la mayoría de los casos resulta ser uno de los principales patógenos que afectan a los frutos maduros en poscosecha (Williamson et al., 2007). Síntomas. En el tomate, su presencia puede examinarse en localizaciones muy distintas de la parte aérea de la planta provocando sintomatologías de variada naturaleza como puede ser cancro del tallo y podredumbre de hojas, flores y frutos recién cuajados. Los frutos maduros pueden ser infectados en almacén, ya que B. cinerea es un importante patógeno de poscosecha (Dal Bello et al., 2012). Agente causal. El fitopatógeno B. cinerea infecta más de 200 especies vegetales, este puede atacar al cultivo en cualquier estado de desarrollo de la planta, puede infectar cualquier parte vegetativa ocasionando pérdidas en frutos tanto en campo como en almacenamiento. Con alta incidencia del patógeno, causa repercusiones económicas en cultivos de importancia tales como vid, tomate, fresa y ornamentales. En el caso de la vid, el patógeno ocasiona importantes pérdidas especialmente en zonas con climas templados y húmedos durante la cosecha (Latorre et al., 1997; Benito et al., 2000; Calvo-Araya et al., 2012). 
Ciclo de vida. Por medio de esclerocios el hongo sobrevive en el suelo, esto es parte de los ciclos secundarios que presenta, en plantas muertas también crece el micelio, otro medio de diseminación se da por medio de semilla contaminada con esclerocios. Existen varias vías de penetración de las esporas como puede ser pétalos de flores senescentes, heridas y follaje moribundo. Los periodos alargados de alta humedad relativa y de bajas temperaturas incrementa la incidencia de la enfermedad. (Latorre et al., 1997). Las esporas de Botrytis cinerea son capaces de ser producidas sobre cualquier material vegetal y trasladadas a distancias considerables por corrientes de aire. Cuando la espora llega a la superficie del huésped comienza el ciclo de infección. El ciclo comprende varias etapas. La primera es la adhesión y germinación de las esporas sobre la superficie del huésped y la segunda, su penetración en el tejido vegetal, ya sea por aberturas naturales o por medio de heridas del tejido. La tercera etapa consta del asentamiento del patógeno en el área de penetración, provocando la muerte de células adyacentes al punto de penetración y originando una lesión primaria causada por la expresión de los mecanismos de defensa de la planta. Como cuarta etapa comienza con una fase de latencia en la cual los mecanismos de defensa de la planta parecen controlar al patógeno, el cual se mantiene en las zonas de necrosis, las cuales se originaron por las lesiones primarias. Durante la quinta etapa, al transcurrir el tiempo, el patógeno es capaz de vencer las barreras defensivas de la planta e inicia su diseminación en el tejido vegetal periférico, determinando la colonización y la maceración del tejido infectado en un corto periodo de tiempo. Sobre el tejido infectado el patógeno produce una nueva generación de esporas que pueden iniciar un nuevo ciclo de infección (Benito et al., 2000). La implementación de prácticas agrícolas oportunas es muy importante para el manejo de la enfermedad, se debe evitar heridas durante las labores de cultivo, así como favorecer la ventilación. Dado que la infección de B. cinerea es favorecida por lesiones en la planta y humedad relativa alta (Salas y Sánchez, 2004). El hongo ha mostrado resistencia a los productos químicos empleados para su control. Además de esta situación los productos disponibles para el control de este hongo se enfrentan cada vez más a la sostenida revisión y revocación de sus usos autorizados y a la vez despiertan una creciente alarma social por los inconvenientes ambientales asociados a su uso (Greer y Diver 1999).

Tizón temprano Alternaria solani (Ell. and Mart.) Jones and Grout. Clase: Deuteromycetes, Orden: Hyphales (Monilialales), Familia: Dematiaceae)

Dentro de los principales patógenos que afectan el tomate se encuentra el tizón temprano (Figura 2). La severidad de esta patología es capaz de disminuir los rendimientos entre un 20-30\% (Martínez et al., 2002). 
En el cultivo de tomate esta enfermedad figura como un grave problema desde la perspectiva económica. Este patógeno tiene un ciclo de vida corto, por ello tiene una gran capacidad de reproducción y de dispersión. Para su control es imprescindible el uso de fungicidas químicos eficientes, sobre todo en los periodos de mayor incidencia de estas patologías. (Muiño et al., 2010). Síntomas. El hongo daña órganos aéreos del tomate, especialmente a las hojas, en las cuales genera manchas necróticas, lo cual reduce la capacidad fotosintética de la planta y en ocasiones puede producir una defoliación grave (Mónaco et al., 2001). En el follaje más viejo se manifiestan los primeros indicios de la enfermedad presentándose áreas irregulares, de color café oscuro y necrótico. Estas lesiones se extienden a medida de que la enfermedad avanza y finalmente desarrollan anillos negros y concéntricos. En el follaje las heridas generalmente están rodeadas por una zona amarilla y clorótica, y si las lesiones son cuantiosas, toda la hoja se torna amarilla y se seca rápidamente. La defoliación completa de la planta puede presentarse en condiciones favorables para el desarrollo de la enfermedad. El desarrollo de las lesiones al nivel del suelo puede causar una pudrición en la copa que generalmente rodea el tallo. Las lesiones en la fruta ocurren normalmente en la punta del cáliz, y son oscuras, correosas y hundidas (López-Vásquez et al., 2013). Agente causal. Alternaría solani presenta un micelio aéreo algodonoso, liso, blanco, que pronto se torna blanco mate a gris y, por último, es capaz de tapar el micelio negro cuando esporula. Los conidióforos son oscuros, de donde nacen los conidios en forma de cadena. Los conidios miden 12-20 X 120-296 $\mu \mathrm{m}$, son oscuros, alargados, ovoides, con apariencia de mazo y presentan septos longitudinales y transversales. (Díaz et al., 1993). Ciclo de vida. En algunas ocasiones es posible que el hongo sobreviva sobre la semilla, sin embargo, lo más común es que el hongo perdure en el suelo encima de remanentes de cosecha infectada o en otras Solanaceas. El origen del inoculo primario es el suelo. Las condiciones climáticas que favorecen el desarrollo de la enfermedad son humedades relativas elevadas que se presentan con días lluviosos y temperaturas entre los 20 y $24{ }^{\circ} \mathrm{C}$. La infección secundaria se provoca cuando las esporas producidas en las plantas infectadas se diseminan a otras plantas a través del aire y precipitaciones. Esta enfermedad es importante en climas áridos al utilizarse riego por aspersión (Sánchez, 2001).

\section{Oidio, Cenicilla u Oidiopsis (Leveillula taurica (Lev.) Arnaud)}

Leveillula taurica (Figura 3), es el hongo patógeno causante de la enfermedad conocida como cenicilla, la cual tiene más de 700 hospedantes, en los cuales destaca el tomate (Solanum lycopersicum) (Guigón-López y González-González, 2001). En el estado de Sinaloa fue donde se identificó por primera vez en México, la cenicilla del tomate causada por L. taurica y 
actualmente puede ser detectada en diversas regiones del país. Para su control en el cultivo del tomate se recurre a la aplicación de fungicidas de origen químico principalmente, lo que representa una proporción alta del costo de producción del cultivo, como es en el caso de la región de la Comarca Lagunera, Coahuila, en donde se realizan hasta 18 aspersiones de fungicidas por ciclo (Guzmán-Plazola et al., 2011). Síntomas. La cenicilla afecta principalmente hojas, tallos, flores y frutos. Los síntomas iniciales son lesiones que van de color verde descolorido a amarillento brillante en la parte superior de las hojas. Después de esto emergen las espoluraciones polvorientas en la parte inferior de las hojas. Conforme progresa la enfermedad las lesiones se vuelven necróticas y la hoja muere. En donde se presenta un microclima apropiado para el desarrollo del hongo causante de la enfermedad, como es el caso de las condiciones en invernadero, las manchas blanquecinas en el haz y en el envés de las hojas son más notorias debido a la mayor densidad de estomas (Elad et al., 2007; Glawe, 2008). Agente causal. El hongo Leveillula taurica es un parásito obligado y típicamente tiene la capacidad de crecer en ausencia de lluvias. Una humedad ambiental de 70$80 \%$ es suficiente para el desarrollo de esta enfermedad que en climas relativamente secos pueden aparecer aprovechándose tan sólo del frescor de la noche. L. taurica es el único miembro de las Erysifáceas cuyo micelio se desarrolla en el parénquima, los demás lo hacen en la superficie de la epidermis. Los conidióforos de L. taurica del tipo oidiopsis son septados y emergen al exterior por los estomas a partir de células endofíticas existentes en los tejidos del hospedante. (Venez et al., 2013). Ciclo de vida. El hongo forma un micelio interno y externo en el hospedante. Los conidios germinan en la superficie del foliolo y se introducen vía estomas; ya que se encuentra en el interior, el hongo crece intercelularmente por tres o cuatro semanas. Posteriormente el micelio emerge por los estomas y se extiende formando conidióforos en la superficie foliar estableciendo colonias blancas las cuales son visibles. En regiones de climas semiáridos y cálidos la cenicilla es una enfermedad común, en estas zonas están presentes una amplia diversidad de hospedantes (Fujiwara et al., 2002; Guzmán Plazola et al., 2011). En el rango de los 10 y $37^{\circ} \mathrm{C}$ sucede la germinación de los conidios y la colonización en los foliolos entre los 15 y $20^{\circ} \mathrm{C}$ y una humedad relativa de 75 a $85 \%$, siendo las condiciones óptimas temperaturas entre los 20 y $25^{\circ} \mathrm{C}$ y una humedad relativa de 80\%. (Huang et al., 1998; Elad et al., 2007). Uno de los métodos de control de la cenicilla más utilizados es el químico, el cual se realiza mediante aspersiones foliares de fungicidas entre los que destacan Azoxystrobin y Myclobutanil, los cuales han mostrado efectividad en la reducción de la severidad de los daños; sin embargo, los efectos varían con el ciclo del cultivo y generalmente son más costosos (Villalobos et al., 2013). 


\section{Tizón tardío Phytopthora infestans (Mont.) de Bary. Phycomycetes: Peronosporales. Pythiaceae}

Agrios (2004), afirma que, esta enfermedad tiene la capacidad de matar las plantas de tomate en dos semanas, incluso en una, cuando las condiciones climáticas son propicias en cualquier momento durante la estación de crecimiento de las plantas y cuando no se aplica ningún método de control. Síntomas. Presencia de lesiones acuosas en los tallos y en las hojas especialmente en el ápice y en el margen de las secciones, acompañado por el desarrollo de un micelio blanquecino. Posteriormente se marchitan y parecen plantas heladas o quemadas. En los frutos, las infecciones se caracterizan por el desarrollo de lesiones acuosas o necróticas café claro, de tamaños y formas muy variables, no llegan a madurar, empardecen y se arrugan (Castaño et al., 1993). Agente causal. Los esporangióforos son ramificados y frágiles. Una característica de la especie es que expresa hinchamientos, encima de los cuales produce las esporas. Los esporangios tienen una longitud estimada de 700 micras, estos aparecen de los estomas. Otra particularidad de los esporangios es que son ovoides en forma de limón, papilados y hialinos. Cuando se presentan temperaturas más cálidas, es posible que se inicien nuevas infecciones penetrando directamente en el tejido mediante un tubo germinativo que produce el esporangio bajo estas condiciones (Castaño et al., 1993). Ciclo de vida. Phytopthora infestans (Figura 4), es atípico, al ser una de las dos únicas especies que son capaces de liberar fácilmente los esporangios al aire seco; estos pueden producir directamente tubos germinativos con temperaturas superiores a $15^{\circ} \mathrm{C}$, pero con mayor frecuencia germinan directamente liberando zoosporas a temperaturas inferiores entre 12 a $15^{\circ} \mathrm{C}$. Los esporangióforos están dilatados en el punto de unión de los esporangios, cada uno de estos puede producir de 8 a 32 zoosporas las cuales diseminan con facilidad una vez que se rompe la pared esporangial (Drenth et al., 2001).

\section{Ahogamiento de plántulas y necrosis radicular Pythium aphanidermatum (Edson) Fitzp. Oomycetes}

El hongo P. aphanidermatum (Figura 5) puede atacar plantas de tomate durante los estados tempranos de crecimiento, causando muerte de plántulas en preemergencia y postemergencia, o podredumbre del tallo. El ataque puede causar grandes pérdidas y crecimiento desigual del cultivo. Las pérdidas ocurren tanto en invernadero como al aire libre (Jones et al., 2001). Síntomas. La muerte de plantas en preemergencia afecta a plántulas que han sido atacadas en los primeros estados de germinación pero con anterioridad a la emergencia. Una lesión castaño oscura o negra se desarrolla rápidamente y afecta toda la plántula. La muerte de plántulas en preemergencia es el síntoma más común asociado a un ataque de Pythium; la enfermedad inicia 
con una lesión oscura y acuosa en la raíz que se extiende a lo largo del tallo o por encima de la línea del suelo. Cuando esta lesión oscura y blanda se desarrolla alrededor de una porción grande del tallo (ahogamiento) o en su totalidad, la planta se dobla, marchita y muere. En la parte de la planta afectada sometidas a una alta humedad puede generarse un crecimiento de micelio de color blanco algodonoso El segundo tipo de enfermedad, cuya importancia se ha reconocido recientemente, es una necrosis radicular que se desarrolla con lentitud a partir del ápice de la raíz hacia atrás, con cambio de coloración a pardo o negro. Lo que ocasiona en la planta un retraso general del crecimiento, con cierto amarillamiento del follaje y perdida de producción. (Punja et al., 2003; Smith et al., 2003). Agente causal. Pythium aphanidermatum forma esporangios relativamente indiferenciados, que en su mayoría no se separan del micelio parental ni se dispersan y que liberan sus contenidos a una vesícula esférica en la que se desarrollan las zoosporas. (Smith et al., 2003). P. aphanidermatum está más asociado con la enfermedad en plántulas que otras especies, especialmente con temperaturas moderadas a altas, ataca en ocasiones a plantas de una longitud de más de 10 cm, causando una lesión húmeda castaño oscuro a negra, que puede llegar a extenderse 2-4 cm por encima del suelo. Generalmente, las plantas afectadas de esta manera se marchitan y mueren (Grijalba et al., 2015). Ciclo de vida. El hongo tiene la capacidad de crecer de forma indefinida en el suelo como micelio vegetativo sobre varios sustratos orgánicos, siempre y cuando cuente con las condiciones propicias. El crecimiento puede ser influenciado por la naturaleza de la base nutritiva, $\mathrm{pH}$, humedad y actividad de microorganismos asociados. La producción de esporas del patógeno es favorecida por la presencia de agua libre en el suelo que puede ser ocasionado por un mal drenaje. Después de germinar, el patógeno puede penetrar a la planta de manera directa, sin embargo, la presencia de heridas incrementa la penetración e infección. Las plantas con exceso de nitrógeno son más susceptibles que las plantas normales. El patógeno produce oosporas de pared engrosada que le permiten sobrevivir bajo condiciones desfavorables en el suelo en ausencia de huésped por largos periodos (Persley et al., 2010).

\section{Marchitez vascular Fusarium oxysporum f. sp. Lycopersici (Sacc.) Snyder y Hansen. Ascomycota}

El hongo Fusarium oxysporum f. sp. lycopersici (Sacc.) Snydery (Figura 6) causa la enfermedad conocida como marchitez vascular la cual es una de las más importantes en el cultivo del tomate ya que puede llegar a mermar en un 60\% el rendimiento (Ascencio-Álvarez et al., 2008). Este hongo se desarrolla en una gran variedad de condiciones ambientales, desde climas templados hasta trópicos (Cai et al., 2003). Se han reportado tres razas del hongo, las cuales se caracterizan por afectar materiales 
diferenciales de tomate que cuentan con distintos genes de resistencia. La primera vez que se describió la raza 1 fue en 1886 y la raza se reportó en 1945 en Ohio. En Australia en 1978 se observó la raza 3, después en varios estados americanos como California, Florida, Arkansas, Tennessee, entro otros. Esta raza también se ha reportado en México. En la actualidad pocas variedades comerciales con resistencia a la raza 3 están disponibles (Cai et al., 2003). Síntoma. El síntoma inicial es amarillamiento de las hojas más viejas; dichos síntomas suelen afectar solo un lado de la planta, y con frecuencia los foliolos a un lado del peciolo se vuelven amarillos antes que los del otro lado. Esta marchitez va avanzando gradualmente en todo el follaje, hasta que la planta muere. La coloración amarillenta del sistema vascular en los tallos es característica de esta enfermedad, si se realiza un corte transversal en el tallo se puede observar un oscurecimiento en los vasos (Momol et al., 2008). Agente causal. El hongo Fusarium oxysporum dentro de sus características morfológicas produce tres tipos de esporas asexuales en cultivo: microconidias, macroconidias y clamidosporas. Las microconidias son rectas o curvadas, hialinas, uniceiulares, pequeñas y de forma oval a elipsoidal, que miden en un rango de 5-12 x 2.2-3.5 micras y son producidas en fiálidos laterales unicelulares y cortos; las macroconidias también son hialinas, generalmente con 3 a 5 septas, semejando una luna en cuarto creciente por su forma curvada en el centro y fina en los extremos, que miden entre 27-60 x 3-5 micras; y las clamidosporas que se producen solas o en pares, de forma intercalar o en ramificaciones laterales cortas, que son estructuras de sobrevivencia del patógeno y tienen forma redonda y paredes delgadas. En medios de cultivo sintético se observa en colonias blancas, cremas, naranjas, pardo, pardo-rojizo, rojo carmín, rosa, púrpura e incluso azuladas dependiendo del aislamiento (Castaño et al., 1994; Osorio-Gutiérrez y Castaño-Zapata, 2011; Villanueva-Arce et al., 2013). Ciclo de vida. La patología marchitez vascular del tomate se presenta generalmente en climas cálidos y en suelos arenosos. El hongo Fusarium oxysporum vive en el suelo, permanece muchos años en suelos infestados. La manera de introducirse a la planta es a través de heridas en la raíz. Temperaturas mayores de $28^{\circ} \mathrm{C}$ es una de las condiciones que beneficia el desarrollo de la enfermedad, así como también la humedad óptima para el desarrollo del cultivo. La virulencia del patógeno se ve aumentada con bajo $\mathrm{pH}$ del suelo así como niveles bajos de $\mathrm{N}$ y $\mathrm{P}$ y altos de $\mathrm{K}$. Existen diferentes formas de diseminación como lo son los tutores de las plantas de tomate, el suelo y las plántulas para trasplante infectadas, o por medio del suelo adherido a estas, así como también por medio de la semilla. Ya establecido el cultivo en el campo la enfermedad se puede dispersar con las herramientas de trabajo, a través de suelo infestado el cual puede diseminarse por agua y viento (Zhang et al., 2011). Existen productos químicos disponibles para su control que 
demostraron tener efecto sobre el micelio, controlando, además, la esporulación del patógeno. Sin embargo, en cuanto a F. oxysporum f. sp. cubense, el uso de variedades resistentes es considerado como el método más efectivo para su control (Araujo et al., 2008).

\section{Podredumbre de cuello y raíz Rhizoctonia solani Kühn (Basidiomycetes: Hymenomycetes)}

Rhizoctonia solani Kühn (Figura 7), es un patógeno habitante del suelo que ataca tomate, sobre todo cuando el sistema de producción es bajo invernadero, este hongo provoca la caída de plántulas y su posterior muerte. Las técnicas de fumigación al suelo como medidas de control, si bien resultan aceptablemente efectivas, son altamente cuestionadas por las alteraciones a la biodiversidad del suelo que estas provocan. Por lo cual, alternativas como la solarización y el uso de biocontroladores se presentan como practicas viables y compatibles con el medio ambiente (Santander et al., 2003). Síntomas. Las plantas infectadas con R. solani entre sus síntomas presentan la pudrición de semillas, ahogamiento y muerte de plántulas, el hongo ataca el tallo iniciando de la parte basal ocasionando pudriciones blandas y pudrición de la raíz, síntomas que resultan debilitando y causando muerte prematura de la planta, en algunos casos, el porcentaje de plántulas muertas puede llegar hasta $70 \%$ lo que ocasiona reducción de la productividad (Arcos y Zúñiga, 2015; Medeiros et al., 2015). Agente causal. Rhizoctonia solani subsiste especialmente en forma de micelio, en su etapa joven este es incoloro y a medida de que madura se torna en un color café claro. La hifa mide de 6 a 12 micras de diámetro, consta de largas células y produce ramificaciones que crecen casi en ángulos rectos $\left(90^{\circ}\right)$ con respecto a la hifa principal, se estrechan ligeramente a nivel de la bifurcación y poseen un septo cerca de ella. Produce esclerocios los que al principio son de color blanco los cuales van obscureciendo a distintos tonos; son irregulares, grandes, miden en un rango de 1 a $8 \mathrm{~mm}$ siendo visibles a simple vista, variables en forma según las condiciones en que se producen, de consistencia dura y en cortes microscópicos muestran una constitución de hifas entrelazadas de diámetro variable (Agrios et al., 2003). Ciclo de vida. Este hongo R. solani requiere de una temperatura óptima para desarrollo en medio de cultivo que oscila entre $25-30{ }^{\circ} \mathrm{C}$ con un mínimo de $8{ }^{\circ} \mathrm{C}$ y un máximo de 31-35 ${ }^{\circ} \mathrm{C}$. Los esclerocios germinan en un rango de 8-30 $\mathrm{C}$ con una temperatura óptima de $23^{\circ} \mathrm{C}$ y a nivel del suelo la temperatura óptima para el ataque del patógeno es de $18{ }^{\circ} \mathrm{C}$. El hongo desarrolla esclerocios negros, los cuales son estructuras de resistencia, los esclerocios germinan, produciendo el micelio cuando se presentan las condiciones favorables, este puede crecer en el suelo, en tallos y en los brotes del cultivo. La penetración de R. solani consiste en el crecimiento de cordones de micelio a lo largo de 
la superficie del brote, las hifas pueden crecer inter o extracelularmente. Rhizoctonia solani se propaga por medio del agua, ya sea por la lluvia o el riego, también por medio de los órganos de propagación infectados. (Mendoza, 1996; Díaz, 2002).

\section{Conclusión}

Una de las zonas de relevancia en la producción de alimentos en la República Mexicana, es el noroeste de México, el cual está conformado por los estados de Baja California, Baja California Sur, Chihuahua, Sinaloa y Sonora. Su producción se ha visto afectada por la aparición de enfermedades que merman su productividad hasta en un 65\% bajo condiciones favorables para los agentes causales de enfermedades. No obstante la alta incidencia de enfermedades presentes en solanáceas como lo es Solanum lycopersicum L., aun no se encuentran suficientemente estudios y documentos en los que las reporten como agentes causales de enfermedades que atacan al cultivo del tomate además de la importancia del diagnóstico fitosanitario en el cultivo del tomate para así poder establecer mejores técnicas de control.

Una enfermedad de una planta puede definirse como cualquier alteración ocasionada por un agente patógeno que afecta la síntesis y la utilización de alimentos, los nutrientes minerales y el agua, de tal forma que la planta afectada cambia de apariencia y tiene una producción menor que una planta sana de la misma variedad.

El diagnóstico de enfermedades en cultivos agrícolas, requiere de conocimiento científico de la fitopatología y disciplinas conexas, del arte de la observación aguda y la búsqueda de claves adecuadas, pues de ello dependerá, en gran medida, la eficacia de las prácticas de regulación que se diseñen y la sostenibilidad económica, social y ambiental de las mismas.

\section{References:}

Agrios, G. Plant pathology. Quinta edición. Editorial Limusa, México D.C. 2004. 310 p.

Araujo, D.; Rodríguez, D.; Sanabria M. E. Respuesta del hongo Fusarium oxysporum f. sp. Cubense, causante del Mal de Panamá, a algunos extractos vegetales y fungicidas. Fitopatología venezolana. 2008. 21(2): 2-8.

Arcos J.; Zúñiga, D. Efecto de rizobacterias en el control de Rhizoctonia solani en el cultivo de papa. Ecología Aplicada. 2015. 14(2): 95-101.

Ascencio-Álvarez, A.; López-Benítez, A.; Borrego-Escalante, F.; RodríguezHerrera S. A.; Flores-Olivas A.; Jiménez-Díaz F.; Gámez-Vázquez A. J. Marchitez vascular del tomate: I. Presencia de razas de Fusarium oxysporum f. sp. lycopersici (Sacc.) Snyder y Hansen en Culiacán, Sinaloa, México. Revista Mexicana de Fitopatología. 2008.26 (2): 114-120. 
Benito, E. P.; Arranz, M.; Eslava, A. Factores de patogenicidad de Botrytis cinerea. Revista Iberoamericana de Micología. 2000. 17: 43-46.

Berenguer, J.J. Manejo del cultivo de tomate en invernadero. En: Curso Internacional de Producción de Hortalizas en Invernadero (Castellanos J.Z. y Muñoz R.J.J. Edit). Celaya, Guanajuato, México. 2003.147-174 pp.

Borboa-Flores, J.; Rueda-Puente, E. O.; Acedo-Félix, E.; Ponce, J. F.; Cruz, M.; Grimaldo-Juárez, O.; García-Ortega, A. M. Detección de Clavibacter michiganensis subespecie michiganensis en el tomate del estado de Sonora, México. Revista Fitotecnia Mexicana. 2009. 32(4): 319-326.

Bustamante, R. E.; Rivas P. G. Elementos e importancia del diagnóstico de problemas fitosanitarios. Rev. Manejo Integrado de Plagas. 1999. (52): 1-15. Cai, G.; Gale, I. R.; Scheider, R.W.; Kistler, H. C.; Davis, R. M.; Elias, K. S.; Miyao E. M. Origin of race 3 of Fusarium oxysporum f. sp. lycopersici at a single site in California. Phytopathology. 2003.93:1014-1022.

Calvo-Araya, J. A.; Rivera-Coto, G.; Orozco-Cayasso, S.; OrozcoRodríguez, R. Aislamiento y evaluación in vitro de la antagonistas de Botrytis cinerea en mora. Agron. Mesoam. 2012. 23(2): 225-231.

Castaño J.; Mendoza, L. D. R. Guía para el diagnóstico y control de enfermedades en cultivos de importancia económica. Zamorano: Escuela Agrícola Panamericana. Honduras. 1994.120-269 pp.

Dal Bello, G.; Nico A.; Mónaco, C. I. Hongos saprófitos como herramientas de control biológico de 'Botrytis cinerea' en tomate. Horticultura global. 2012. (303): 64-68.

De Santa Olalla, M. F.; López F. P.; Calera B. Agua y Agronomía. Editorial Mundi-Prensa. España. 2005. 330p.

Díaz, B. V. Principales enfermedades del frijol ejotero (phaseolus vulgaris L.) en las principales regiones productoras del estado de Morelos. INIFAP. Folleto técnico. 2002. 17. 34 p.

Díaz, F. A.; Rocha P. M.; Castrejón S. A. Enfermedades infecciosas de los cultivos. Editorial trillas. México. 1993.146p.

Díaz, M. Ecología experimental y ecofisiología: bases para el uso sostenible de los recursos naturales de las zonas áridas no-tropicales. Interciencia. 2001.26 (10): 472-478.

Drenth, A.; Sendall B. Practical guide to detection and identification of Phytophthora. CRC for Tropical Plant Protection, Indooroopilly Research Centre Plant Pathology Building. Australia. 2001.1-41pp.

Elad, Y.; Messika, Y.; Brand, M.; David, D.; Sztejnberg, A. Effect of microclimate on Leveillula taurica powdery mildew of sweet pepper. Phytopathology. 2007. 97:813-824.

FAOSTAT. Estadísticas datos agrícolas. http://faostat3.fao.org/browse/Q/QC/S (Consultada el 15 septiembre de 2015). 2015. 
Figueroa, L.P.; Moreno, B. A.; Valenzuela, V. J. M.; Tamayo, E. L. M.; Armenta C. I. Etiología, epidemiología y manejo de enfermedades virales en papa y chile en el sur de sonora. Memoria día del agricultor, Campo experimental Valle del Yaqui INIFAP. Sonora, México. 2007.14: 74-76

Fujiwara, K.; Fujii, T. Effects of spraying ozonated water on the severity of powdery mildew infection on cucumber leaves. Ozone Science and Engineering. 2002.24:463-469.

Glawe, D. A. The powdery mildews: A review of the world's most familiar (yet poorly known) plant pathogens. Ann. Rev. Phytopathol. 2008. 46: 2751.

Greer, L.; Diver, S. Integrated pest management for greenhouse crops. Pest management systems guide. Appropriate Technology Transfer in Rural Areas ATTR). 1999. publ. \# IP 144. 34 p.

Grijalba, P. E.; Zapata, R. L.; Palmucci, H. E.; Baron, C. Podredumbre basal de plantas adultas de tomate causada por Pythium aphanidermatum (Oomycota). Boletín de la Sociedad Argentina de Botánica. 2015. 50(1):1115.

Guigón-López, C.; González-González P. Estudio regional de las enfermedades del chile (Capsicum annum, L.) y su comportamiento temporal en el sur de Chihuahua, México. Revista Mexicana de Fitopatología 2001.19: 49-56.

Guzmán-Plazola, R. A.; Fajardo-Franco, M. L.; García-Espinosa R.; CadenaHinojosa M. A. Desarrollo epidémico de la cenicilla y rendimiento de tres cultivares de tomate en la comarca lagunera, Coahuila, México. Agrociencia. 2011. 45(3): 363-378.

Hernández-Herrera, R. M.; Santacruz-Ruvalcaba F.; Ruiz-López M. A.; Norrie J.; Hernández-Carmona G. Effect of liquid seaweed extracts on growth of tomato seedlings (Solanum lycopersicum L.). Journal of applied phycology. 2014.26(1): 619-628.

Huang, C. C.; Groot, T.; Meijer-Dekens, F.; Niks, R. E.; Lindhout, P. The resistance to powdery mildew (Oidium lycopersicum) in Lycopersicon species is mainly associated with hypersensitive response. European J. Plant Pathol. 1998. 104(4):399-407.

Jiménez, D. F. Enfermedades del Tomate (Lycopersicon esculentum Mill.) Ed. Limusa. México, D.F. 2003. 102 p.

Jones, J.B.; Stall, R. E.; Zitter, T. A. Plagas y enfermedades del tomate. Ediciones Mundi-Prensa. México, D.F. 2001.74 p.

Latorre, B. A.; Agostín E.; San Martín, R.; Vázquez, G. S. Effectiveness of conidia of Trichoderma harzianum produced by liquid fermentation against Botrytis bunch rot of table grape in Chile. Crop Protection. 1997. 16 (3): 209- 214. 
López-Aguilar, R.; Murillo-Amador, B.; Rodríguez-Quezada, G. El forraje verde hidropónico $(\mathrm{FVH})$ : Una alternativa de producción de alimento para el ganado en zonas áridas. Interciencia. 2008. 34 (2): 121-126.

López-, J. M.; Marulanda M. L.; López A. M. Factores climáticos y su influencia en la expresión de enfermedades fúngicas en cultivares de Heliconias. Universitas Scientiarum. 2013. 18(3), 331-344.

Martínez, B.; Bernal, A.; Pérez, S.; Muñiz, Y. Variabilidad patogénica de aislamientos de Alternaria solani Sor. Rev Protección Veg. 2002. 17(1):4553.

Mazuela, Á. P. C. Agricultura en zonas áridas y semiáridas. Idesia (Arica). 2013.31(2): 3-4.

Medeiros, A. C., Melo D. R. M. D., Ambrósio M. M. D. Q., Nunes G. H. D. S. y Costa J. M. D. 2015. Methods of inoculation of Rhizoctonia solani and Macrophomina phaseolina in melon (Cucumis melo). Summa Phytopathologica 41(4): 281-286.

Mendoza, Z. C. Enfermedades Fungosas de Hortalizas. Chapingo, México. 1996. 55 p.

Mónaco, C.; Nico, A.; Rollán, M.; Urrutia, M. Efecto in vitro de dos fungicidas sobre la micoflora antagonista al tizón temprano del tomate. Investigación agraria. Producción y protección vegetal. 2001.16 (3): 326332.

Muiño, B. L.; Almándoz, P. J.; Triane, E. M. Efecto in vitro del fungicida iprodione sobre alternaria spp. y prospección para su inclusión en estrategias de manejo en papa, tomate, ajo y cebolla. Fitosanidad. 2010.14 (3): 171-176. Osorio-Gutiérrez, L. A.; Castaño-Zapata, J. Caracterización del agente causante de la Pudrición de raíces de la arveja (Pisum sativum Linneo), enfermedad endémica en el municipio de Manizales-Caldas (Colombia). Agronomía. 2011. 19 (2): 33-43.

Pelegrín, L. S.; Arias, A.P.; Fajardo, J. P.; Vega, C. T. Diferenciación de variedades de tomate frente al tizón temprano (Alternaria solani) en dos épocas de siembra en el Valle del Cauto. Granma Ciencia. 2004.8 (2): 1-3.

Persley, D.; Cooke, T.; House, S. Diseases of Vegetable Crops in Australia. CSIRO Publishing. 2010. 304 p.

Polanco, J. Uso de alternativas de reemplazo a los ditiocarbamatos en la prevención de Phytophtora infestans causante del tizón tardío en el cultivo de tomate riñón (Solanum lycopersicum), cultivado a campo abierto en el sector de Cuambo cantón Ibarra. Tesis Doctoral. Saltillo, Coahuila, México. 2012. 93 p.

Punja, Z. K.; Yip R. Biological control of damping-off and root rot caused by Pythium aphanidermatum on greenhouse cucumbers. Canadian Journal of Plant Pathology. 2003. 25:4, 411-417 
Rodríguez-Caro, M.A.; Serrano-Cely P.A.; Forero-Ulloa F. Evaluación del desarrollo de tomate (Solanum licopersicum) bajo dos tipos de cubiertas plásticas en Piedecuesta, Santander. Ciencia y Agricultura. 2009.7(2): 17-30. Rodríguez, J. M. M. Acuíferos y agroquímicos en una región fronteriza: retos y oportunidades del TLCAN para la agricultura mexicana, Hermosillo, Son., Red Fronteriza de Salud y Ambiente, Universidad de Sonora, Comisión de Cooperación Ambiental. 2003. 35 p.

Rodríguez, A. O. V.; Sierra, Á. B. Procesos de aprendizaje y modernización productiva en el agro del noroeste de México: Los casos de la agricultura comercial de la Costa de Hermosillo, Sonora y la agricultura orgánica de la zona sur de Baja California Sur. Estudios Fronterizos, Revista de Ciencias Sociales y Humanidades. 2013. 14(27): 217-254.

SAGARPA. 2005., Análisis Agropecuario del Tomate. Boletín Informativo. Culiacán, Sinaloa, México. 9 p.

Salas B. W. y Sánchez G. V. Avances en el control biológico de Botrytis cinerea en chile y tomate cultivados bajo techo. Semana Científica 2004. Memoria. 6. Semana Científica. 2004.111-112.

Sánchez, C. M. Manejo De enfermedades del tomate. Curso del INCAPA "Manejo integrado de plagas y enfermedades en tomate, chile y papa". Guadalajara, Jalisco, México. 2001.22-39.

Sandoval, B. C. Manual Técnico. Manejo Integrado de Enfermedades en Cultivos Hidropónicos Agricultura y la Alimentación. FAO, Oficina Regional Para América Latina y el Caribe. 2004. 53 p.

Santander, C.; Montealegre, J.; Herrera, R. Control biológico de Rhizoctonia solani en tomate en suelos previamente sometidos a solarización y bromuro de metilo. Ciencia e Investigación Agraria. 2003. 30 (2): 107-112.

SIAP, Servicio de Información Agropecuaria y Pesquera. Anuario agropecuario 2000-2014. Disponible en: http://www.siap.gob.mx/ (consulta: 10 Marzo 2016). 2015.

Smith, I. M.; Phillips, J.; Lelliott, D. H.; Archer, S. A. Manual de enfermedades de las plantas. Mundi-Prensa. España. 1992. 671p.

Venez, F.; Cedeño, L.; Rodríguez, L. A.; Quintero, K. Primer reporte en Venezuela de mildiú polvoriento causado por Leveillula (oidiopsis) taurica en lisiantus. Fitopatología Venezuela. 2009.22:23-24.

Villa R. A. O.; Bracamonte S. A. Procesos de aprendizaje y modernización productiva en el agro del noroeste de México: Los casos de la agricultura comercial de la Costa de Hermosillo, Sonora y la agricultura orgánica de la zona sur de Baja California Sur. Estud. Front. 201214 (27): 1-27.

Villalobos, R.; Reyes S.; González, R.; Pérez, E.; Dorantes, G. A.; Bobadilla, M. Prevención de cenicilla con azufre sublimado en pimiento y tomate en invernadero. INIFAP (instituto nacional de investigaciones forestales, agrícolas 
pecuarias).http://biblioteca.inifap.gob.mx:8080/jspui/bitstream/handle/12345 6789/3944/CIRCE_010208221600049272ok.pdf?sequence=1 (Consulta: 13 octubre 2015). 2013.

Villanueva-Arce, R.; Aguilar-Pompa, C. A.; Gómez, V. D.; Piña-Guzmán, A.; Bautista-B. Control de bacterias patógenas y hongos de postcosecha con extractos del pigmento de Gibberella zeae (Fusarium graminearum). Agrociencia. 2013.47(7): 691-705.

Villa, R. A. O.; Bracamonte, S. Á. Procesos de aprendizaje y modernización productiva en el agro del noroeste de México: Los casos de la agricultura comercial de la Costa de Hermosillo, Sonora y la agricultura orgánica de la zona sur de Baja California Sur. Estudios fronterizos. 2013.14 (27): 217-254. Williamson B.; Tudzynski ,B.; Tudzynski, P.; Van Kan, J. Botrytis cinerea: the cause of grey mould disease. Mol Plant Pathol. 2007.8: 561-580.

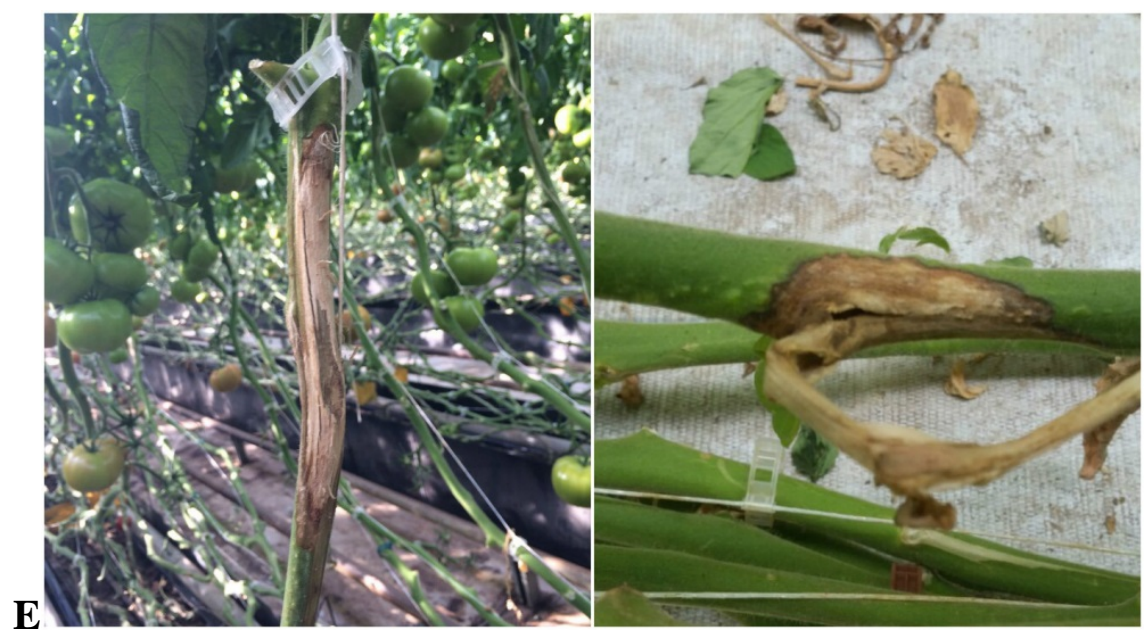

Figura 1. Hongo Botrytis cinerea en tallo de plantas de tomate (Solanum lycopersicum L.)

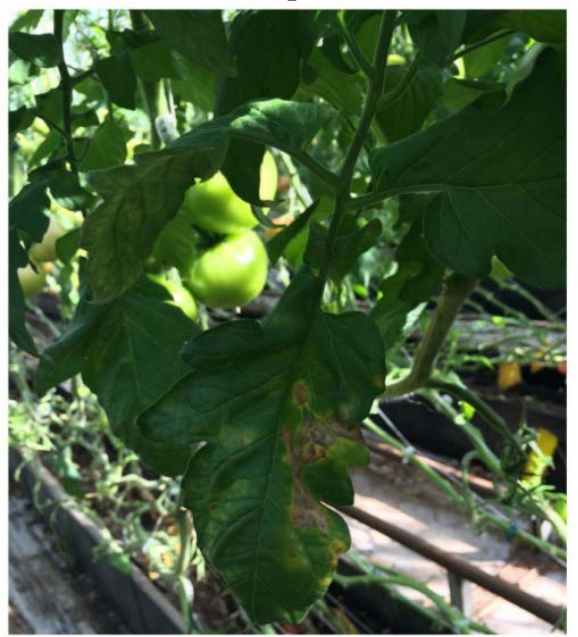

Figura 2. Hongo Alternaría solani en hojas de plantas de tomate (Solanum lycopersicum L.) 


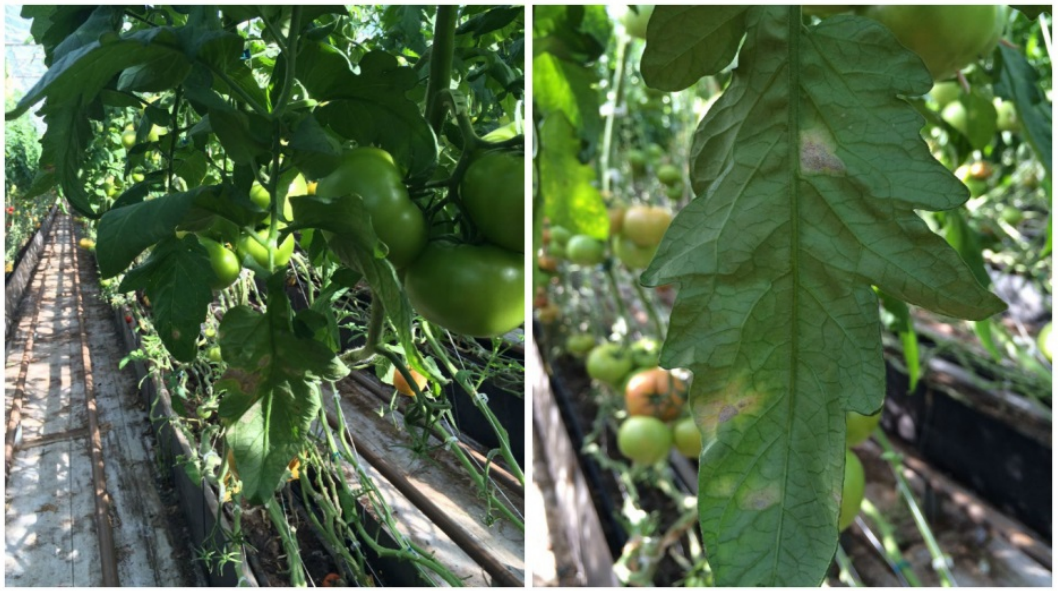

Figura 3. Hongo Leveillula taurica en hojas de plantas de tomate (Solanum lycopersicum L.) .

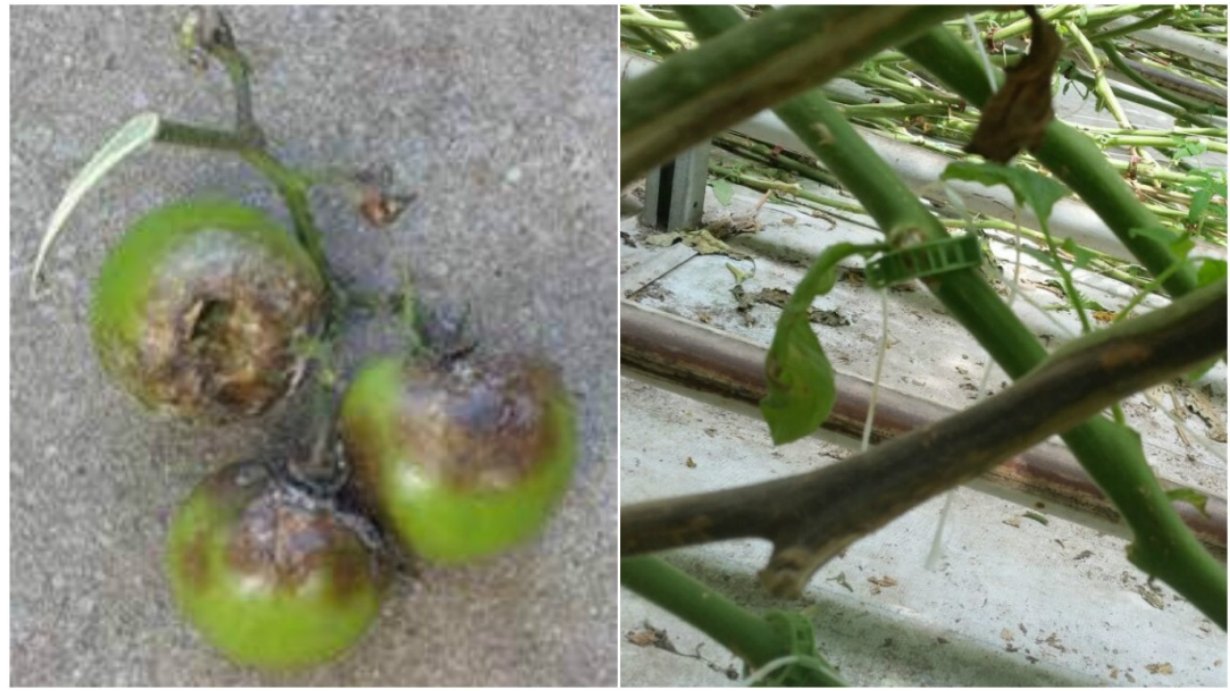

Figura 4. Hongo Phytopthora infestans en fruto y tallo de tomate (Solanum lycopersicum L.).

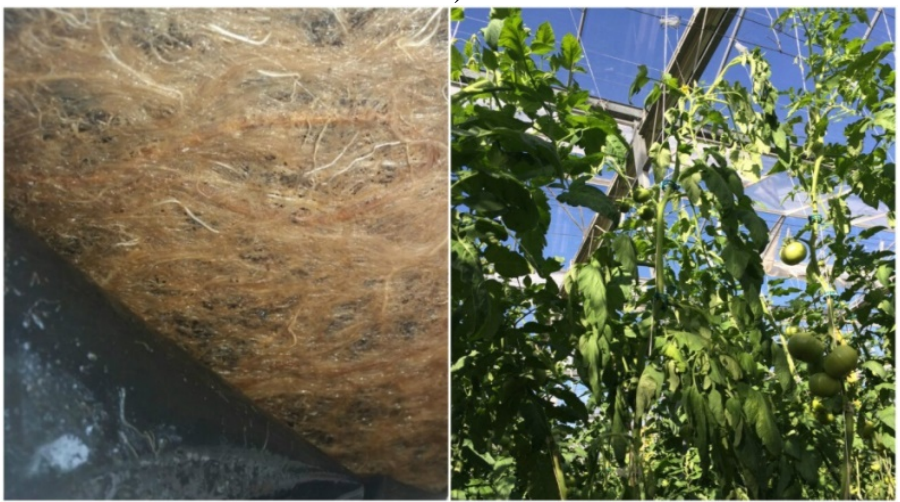

Figura 5. Hongo Pythium aphanidermatum en raíz y planta de tomate (Solanum lycopersicum L.) 


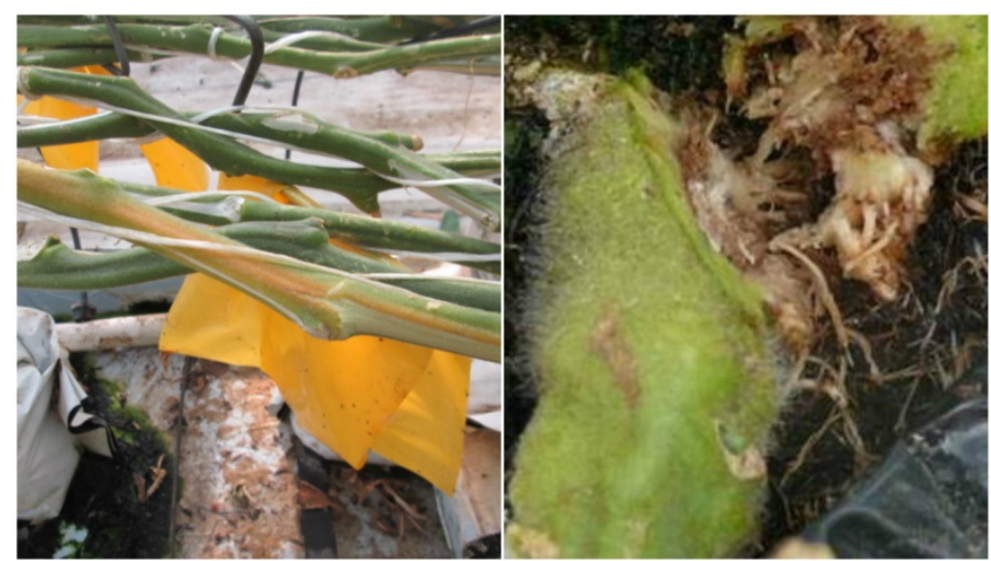

Figura 6. Hongo Fusarium oxysporum en tallo de tomate (Solanum lycopersicum L.).

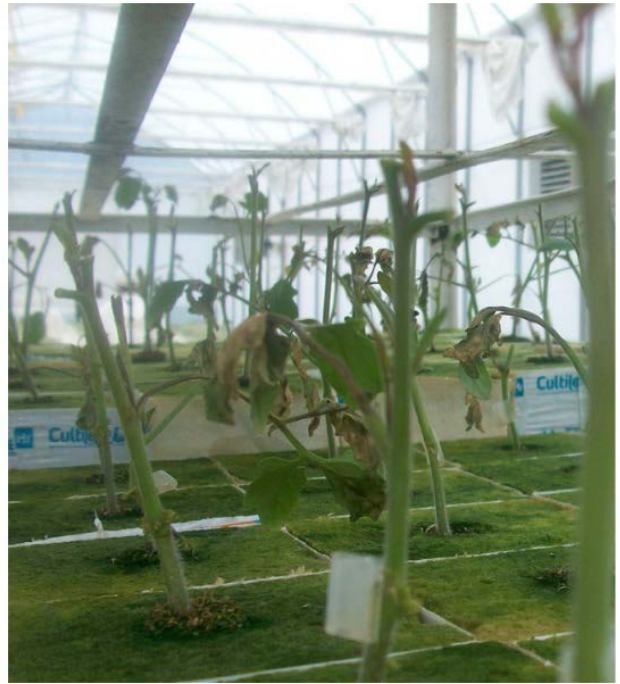

Figura 7. Hongo Rhizoctonia solani en plántula de tomate (Solanum lycopersicum L.) 